\title{
Assessment of Factors Affecting Vaccine Cold Chain Management Practice in Bahir Dar City Health Institutions, 2019
}

\author{
Sileshi Mulatu*, Getasew Tesfa, Habitamu Dinku \\ Department of Paediatrics and Child Health Nursing, College of Medicine and Health Sciences, Bahir-Dar University, Bahir-Dar, Ethiopia \\ Email address: \\ silshimulatu@gmail.com (S. Mulatu),getasewtesfa@yahoo.com (G. Tesfa), habtamudinku4@gmail.com (H. Dinku) \\ ${ }^{*}$ Corresponding author
}

To cite this article:

Sileshi Mulatu, Getasew Tesfa, Habitamu Dinku. Assessment of Factors Affecting Vaccine Cold Chain Management Practice in Bahir Dar City Health Institutions, 2019. American Journal of Life Sciences. Vol. 8, No. 5, 2020, pp. 107-113. doi: 10.11648/j.ajls.20200805.14

Received: May 3, 2020; Accepted: June 3, 2020; Published: August 27, 2020

\begin{abstract}
Background: Vaccines are the only essential commodities that required their own specific supply chain system with storage of $2^{\circ} \mathrm{C}$ to $8^{\circ} \mathrm{C}$. It is critical that they should be kept at appropriate temperatures during transit and storage. Objective: The purpose of this study was to assess vaccines' cold chain management practice at public health facilities in Bahir Dar City health institutions. Methods: Institutional based cross-sectional study was conducted from January 5 to January 12 2019 in Bahir Dar City, Amhara Regional State, and Northwest Ethiopia. The information was collected by an interviewer administered, pre-tested and structured questionnaire in health center and hospital in Bahir Dar city. Data was entered and analyzed using SPSS version 20 software. Descriptive statistics and Logistic regression analysis were carried out to identify factors related to the practice of cold chain management. Result: From a total of health facility $9(64.3 \%)$ had functional thermometer, $14(100 \%)$ had an electrical power source refrigerator, and $10(71.4 \%)$ had functional generator for backup service. $9(64.3 \%)$ had guide line in the facility. From a total of health facility $10(71.4 \%)$ had monitor temperature twice daily in there facility. Among the factors, only work experience and level of knowledge on vaccine cold chain management had a statistically significant association with the practice of health workers on cold chain management. The adjusted model indicated that respondents who had good level knowledge were 2.6 times more likely to have proper cold chain management practice as compared with those who had not. Health workers whose work experience more than two years were about 5 times more likely to have proper practice on cold chain management compared to their counterpart with $95 \% 5.2(1.4-19.14)$ and 95\% 1.97 (0.77-5.03). Conclusion and recommendation: Respondents had adequate knowledge and the cold chain equipment was not in a good condition and we would like to recommend On-going follow up should be given to continue their strength
\end{abstract}

Keywords: Vaccine, Cold Chain, Cold Chain Management Practice

\section{Introduction}

Vaccination is the intervention that is taken for the prevention and eradication of vaccine preventable disease. Vaccination is the most precious gift that a health care worker can give a child to prevent from disease causing microbes [1]. It remains the most cost effective preventative health intervention presently known and applicable in most health institutions and it is important for the prevention of two and three million deaths globally each year [2]. Ethiopia, as one of the member states, adopted EPI in 1980 [3]. To save lives of millions of infants and young children dying from vaccine preventable diseases, namely tuberculosis, tetanus, whooping cough, diphtheria, poliomyelitis and measles, the Expanded program on Immunization (EPI) was launched by WHO in 1974 [4]. A set of practice guidelines for different service levels were created by the World Health Organization (WHO), which include vaccine monitoring, immunization techniques, cold chain management and reporting systems [3, 5].

The cold chain is the system of transporting and storing of vaccine at the recommended temperature range which is $\left(+2^{\circ} \mathrm{C}\right.$ to $+8^{\circ} \mathrm{C}$ for refrigerator vaccines) and $\left(-15^{\circ} \mathrm{C}\right.$ to $25^{\circ} \mathrm{C}$ for freezer vaccines). Cold chain begins from the time the vaccine is manufactured, stored, distributed and ends 
when it is administered to client [1]. It consists of a series of storage and transport links, all designed to keep vaccines within an acceptable temperature range until it reaches the users. The success of the EPI is therefore highly sensitive to the cold chain status and hence its management should not be taken lightly [6].

All in health facilities and during immunization sessions, World health organization $/ \mathrm{WHO} /$ recommended to store all vaccines between $+2^{\circ} \mathrm{C}$ and $+8^{\circ} \mathrm{C}$ in the refregrators. However, these guidelines are often practically quite difficult to implement in practically in the field at the end users due to various factors like poor infrastructure, poor skill manpower and workload. Successful immunization programs are built on functional end-to-end supply chain and logistics systems. The role of the supply chain is to ensure effective vaccine storage, handling, and stock management, rigorous temperature control in the cold chain, maintenance of adequate logistics and information system management [7].

In the health facility the vaccines should be maintain its efficacy and potency by using temperature monitoring devices (i.e. by applying cold chain system) and insured by trained personnel during transporting, storing and administering [8, 9]. Appropriate usage of cold chain system and high coverage rates is considered one of the indicator of success of the immunization program $[1,9,10]$.

In developed nation the cold chain system are at great risk, since power supply, transportation and skilled manpower is unreliable and health facilities are with a problem of monitoring the temperature in the freezer or refrigerator, store vaccines in appropriate temperature, and transporting to the end users or immunization session.

The efficacy of vaccines may be compromised due to several factors including the temperature at which the vaccine is stored in a refrigerator $[11,12]$ it is not uncommon to observe, at any given time, between $30-50 \%$ of the refrigerators and freezers being out of order. A study from Ghana reported that only $64 \%$ of the functioning refrigerators were maintained at temperatures required for safe vaccine storage [10].

In the last decade, most countries in the world were achieved high immunization coverage [13]. Due to cold chain failure 2.8 million vaccine doses lost in five countries [14]. In addition, in more than 70 countries between 2010 and 2012 found that only $29 \%$ of countries met its minimum recommended standards for temperature control and merely less than $10 \%$ of countries met out of 24 countries in 2013 $[15,16]$. Vaccine potency was highly sensitive to the cold chain status. So that vaccine lost its potency when exposed to excessive heat, cold, or light and once it loses its potency cannot be restored and people who receive the vaccine with reduced potency may not be fully protected against vaccine preventable diseases $[12,17,18]$. The vaccine supply chain in Ethiopia was characterized as "inefficient and unacceptable", and distribution was described as "chaotic" $[4,8,13]$

Cold chain management weaknesses are often observed during transportation and storage of the vaccines. Some factors contributing to weaknesses of the cold chain are delays during transportation, quality of refrigerators, a method of storage, too long storage at the health unit, improper use of refrigerators, power interruption, equipment breakage, and lack of trained personnel capable of managing the cold chain. A study Southeast Ethiopia, only 56 (30.6\%) health facilities had refrigerator, out of 35 functional refrigerators, $20(57.1 \%)$ had national cold chain monitoring guideline and only $14(40 \%)$ were properly store vaccines [9, $12,16,19]$. The aim of this study is to assess the factors affecting management and quality of the cold chain in immunization health institutions in Bahir Dar city.

\section{Methods and Materials}

\subsection{Study Design, Period and Area}

The institution-based cross-sectional study design was conducted from January 5 to January 12, 2019 in in Bahir Dar City; capital city of Amhara Region. It is $568 \mathrm{KM}$ distant from the capital city of Ethiopia, Addis Ababa. The altitude of the BahirDar city is between 648 and 1300 meters above sea level. According to Bahir Dar Zonal Health Department child and Nutrition officer report, the town has 10 health center, 2 Governmental Hospital, 3 private Hospital and 10 Clinics.

\subsection{Sample Size Determination, Sampling Procedure and Study Population}

The sample size was estimated using a single population proportion formula for a cross-sectional study. It was calculated by assuming prevalence (P) was 50 and through consideration of the following critical assumptions. Such as, a $95 \%$ of confidence level and 5\% margin of error (d). Fourteen health institution ( 9 health center and 5 health post) were selected respectively from 24 health institution by simple random sampling. From the selected health institution, 9 were health center and 5 health posts which have refrigerators for vaccine storage and the cold chain storekeeper were interviewed at facility level, the under-five focal person (responsible person at immunization ward) was interviewed at the health center, and the health extension workers (community health workers) were interviewed at health post level until we reached final sample size.

\subsection{Data Collection Procedure and Tools}

The data was collected by using a structured questionnaire prepared for this study as shown in Additional file 1, which consists of four main categories namely socio-demographic variables, cold room infrastructure status, cold chain management knowledge which contain 7 items, and cold chain management practice variables which contain 13 items.

The level of knowledge computed by considering the normal distribution of the data, a mean value 5 or above $(\geq 75 \%$ ) was considered as an appropriate cut-off point to classify knowledge as sufficient or insufficient. The level of practice was computed by considering the normal 
distribution of the data, a mean value 10 or above ( $\geq 75 \%)$ was considered as an appropriate cut-off point to classify cold chain practice as proper or improper practice [8].

\subsection{Data Quality Management Analysis}

Two days of training was given to employed data collectors and supervisors. The training was mainly focused about study objective, mechanism of interview, ways of data collection, and relevant ethical issues during data collection process. The questionnaire was pre-tested among a total 3 health centers in out of the study area. During the pre-test, order and clarity of questionnaire, sensitiveness, ambiguity, and options for the questions and skipping pattern was evaluated accordingly. Furthermore, to ensure the consistency and data quality, the questionnaire prepared in English language and translated into the local language then back into English version. All the interviews were conducted with mother/responsible caretakers of a child. Moreover, all questionnaires were checked for completeness, clarity and consistency by the respective supervisors, in day to day of data collection period. The investigators were coordinated the overall activities of data collection. The principal investigator was coordinated the overall data collection process

The analysis was started by data entering, coding and cleaning. Data entry into the computer was carried out using the Epi info version 7. After completion of data entry, the data was exported to SPSS software version 20 for analysis. Frequencies and cross-tabulations were used to summarize descriptive statistics of the data. Bivariate logistic regression was employed to see the association of each variable with dependent variables. Finally, independent variables with p-values less than 0.2 in the bivariate logistic regression were entered to multivariate logistic regressions to control the effect of confounding. Furthermore, analysis and variables having $\mathrm{P}-$ values of less than $5 \%$ was considered as variables which has significant association with outcome variable.

\subsection{Ethical Considerations}

The ethical clearance for the present study was obtained from the institutional review board of Institute of Public Health, College of Medicine and Health Sciences, the Bahir Dar University. The ethical clearance was submitted to Pawie District Health Office. An official permission letter for the next steps was obtained from the Office. The written permission letter from the district health office was submitted to each health center and health post, which is the actual data collection was carried out. All health care workers who are were EPI focal were informed about the objective of the study. Oral consent was done with the participant, right to withdraw from the study at any time, without any requirement was disclosed clearly. Furthermore, the confidentiality of the information obtained from participants and from the unite was guaranteed by all data collectors and investigators by using code numbers and keeping the questionnaires

\section{Result}

Sociodemographic Result

All 14 health facilities were participated (overall response rate was $100 \%$ ). Among a total of 14 health facilities, almost all health care provider how working in the vaccination centre were took pre-service and in-service training. From a total of health facility $9(64.3 \%)$ had functional thermometer, $14(100 \%)$ had an electrical power source refrigerator, and 10 $(71.4 \%)$ had functional generator for backup service. 9 $(64.3 \%)$ had guide line in the facility. From a total of health facility $10(71.4 \%)$ had monitor temperature twice daily in there facility and $3(21.4 \%)$ health facility were had expired vaccine in the refregrators. Among the vaccine providers included in the study, $9(64.3 \%)$ were females, $6(42.9 \%)$ were clinical nurse, $3(21.4 \%)$ were pharmacy and BSc nurse and $2(14.3 \%)$ were health officer. Among these health care providers, $12(85.7 \%)$ of the respondents had $>2$ years of experience. (Tabl 1)

Table 1. Socio demographic characteristics of respondents, Bahir Dar City, 2019.

\begin{tabular}{|c|c|c|c|c|}
\hline Ser no & Variable & Category & Frequency & Percent \\
\hline \multirow{3}{*}{101} & \multirow{3}{*}{ Age } & less than 25 & 8 & 57.1 \\
\hline & & $26-35$ & 3 & 21.4 \\
\hline & & $\begin{array}{l}\text { Greater than } \\
35\end{array}$ & 3 & 21.4 \\
\hline \multirow{4}{*}{102} & \multirow{4}{*}{ Qualification } & Clinical Nurse & 6 & 42.9 \\
\hline & & $\begin{array}{l}\text { Pharmacy } \\
\text { Technician }\end{array}$ & 3 & 21.4 \\
\hline & & BSC Nurse & 3 & 21.4 \\
\hline & & Health officer & 2 & 14.3 \\
\hline \multirow{2}{*}{103} & \multirow{2}{*}{ Work experience } & $1-2$ years & 2 & 14.3 \\
\hline & & $>2$ years & 12 & 85.7 \\
\hline \multirow{2}{*}{104} & \multirow{4}{*}{$\begin{array}{l}\text { Did you } \\
\text { undergone pre } \\
\text { service training? } \\
\text { Have you ever } \\
\text { attended in service } \\
\text { training? }\end{array}$} & Yes & 14 & 100 \\
\hline & & No & 0 & 0 \\
\hline \multirow{2}{*}{105} & & yes & 12 & 85.7 \\
\hline & & no & 2 & 14.3 \\
\hline
\end{tabular}

Cold chain Status of Facility

Among the total health facility 10 (71.4\%) had sufficient vaccine room storage capacity. All facility were arranged the vaccines in refrigerator properly. From the total health facility $10(71.4 \%)$ the cold room were clean free of dirt and all the roof were free of leak. $8(57.1 \%)$ of the facility had sufficient area to store all vaccines in the cold room.

More than two third, $10(71.4 \%)$ of the facility had separate storage area for vaccine and almost all facility windows and external room security were maintained. Majority $11(78.6 \%)$ of vaccine storage in the refrigerator was properly. $14(100 \%)$ of health institution main source of power is electricity. (Table 2) 
Table 2. Health worker reported status of vaccine cold room in health institutions Bahir Dar Town, 2019.

\begin{tabular}{|c|c|c|c|c|}
\hline No & Variable & Category & Frequency & Percent \\
\hline \multirow[b]{2}{*}{201} & \multirow{2}{*}{$\begin{array}{l}\text { Have a sufficient } \\
\text { storage capacity in your } \\
\text { facility? }\end{array}$} & yes & 10 & 71.4 \\
\hline & & no & 4 & 28.6 \\
\hline \multirow[b]{2}{*}{202} & \multirow{2}{*}{$\begin{array}{l}\text { Is there vaccine } \\
\text { ordering and reporting } \\
\text { form? }\end{array}$} & Yes & 7 & 50 \\
\hline & & No & 7 & 50 \\
\hline \multirow[b]{2}{*}{203} & \multirow{2}{*}{$\begin{array}{l}\text { Availability of } \\
\text { functional } \\
\text { thermometers? }\end{array}$} & Yes & 9 & 64.3 \\
\hline & & No & 5 & 35.7 \\
\hline \multirow{2}{*}{204} & \multirow{2}{*}{$\begin{array}{l}\text { Is daily temperature is } \\
\text { record? }\end{array}$} & Yes & 4 & 28.6 \\
\hline & & No & 10 & 71.4 \\
\hline \multirow{2}{*}{205} & \multirow{2}{*}{$\begin{array}{l}\text { Freezer working } \\
\text { condition? }\end{array}$} & Yes & 11 & 78.57 \\
\hline & & No & 3 & 21.43 \\
\hline \multirow{2}{*}{206} & \multirow{2}{*}{$\begin{array}{l}\text { Is there functional } \\
\text { thermometer? }\end{array}$} & Yes & 9 & 64.3 \\
\hline & & No & 5 & 35.7 \\
\hline \multirow[b]{2}{*}{207} & \multirow{2}{*}{$\begin{array}{l}\text { Vaccine storage in } \\
\text { recommended } \\
\text { temperature }\end{array}$} & ye & 14 & 100 \\
\hline & & No & 0 & 0.00 \\
\hline \multirow{2}{*}{208} & \multirow{2}{*}{$\begin{array}{l}\text { Vaccines are kept in the } \\
\text { proper compartment }\end{array}$} & Yes & 11 & 78.6 \\
\hline & & No & 3 & 21.4 \\
\hline \multirow{2}{*}{209} & \multirow{2}{*}{ Main source of power } & electricity & 14 & 100 \\
\hline & & kerosene & 0 & 0.00 \\
\hline \multirow{2}{*}{210} & \multirow{2}{*}{$\begin{array}{l}\text { Is the Refrigerators } \\
\text { functional? }\end{array}$} & Yes & 14 & 100.00 \\
\hline & & No & 4 & 0.00 \\
\hline \multirow{2}{*}{211} & \multirow{2}{*}{$\begin{array}{l}\text { Is there any expired } \\
\text { vaccine in the } \\
\text { refrigerator? }\end{array}$} & yes & 11 & 78.6 \\
\hline & & no & 3 & 21.4 \\
\hline \multirow{2}{*}{212} & \multirow{2}{*}{$\begin{array}{l}\text { Does separate } \\
\text { temperature record }\end{array}$} & yes & 12 & 85.7 \\
\hline & & no & 2 & 14.3 \\
\hline \multirow[b]{2}{*}{213} & \multirow{2}{*}{$\begin{array}{l}\text { Dose vaccine carrier } \\
\text { should have Ice pack } \\
\text { and foam pad }\end{array}$} & Yes & 14 & 100.0 \\
\hline & & No & 0 & 0 \\
\hline \multirow{2}{*}{214} & \multirow{2}{*}{$\begin{array}{l}\text { VVM should be used to } \\
\text { monitor each vaccine }\end{array}$} & Yes & 8 & 57.1 \\
\hline & & No & 6 & 42.9 \\
\hline & Is the cold room clean, & Yes & 10 & 71.4 \\
\hline 215 & free of dirt & No & 4 & 28.6 \\
\hline & Windows and external & Yes & 13 & 92.9 \\
\hline 216 & room security & No & 1 & 7.1 \\
\hline & & Yes & 14 & 100.0 \\
\hline $2 \mathrm{\Gamma} 7$ & Roof free of leaks & No & 0 & 0.00 \\
\hline & Dryness of floor and in & Yes & 11 & 78.6 \\
\hline 218 & reasonable level & No & 3 & 21.4 \\
\hline
\end{tabular}

Knowledge of Respondents on Cold Chain

All of the respondents knew that the correct placement of vaccines in the refrigerator is $2-8^{\circ} \mathrm{C}$. Nine $(64.3 \%)$ of respondents knew that vaccine are heat sensitive and all of the respondent knew that freeze is harm to vaccine. thirteen $(92.9 \%$ of the respondents knew that the correct placing practice of thermometer and $11(78.6 \%)$ of the health care workers knew that the correct demonstration of temperature reading, although $85.7 \%$ of respondents knew that the correct interpretation of shake test. All of the respondents had correctly interpreted the vaccine vial monitor (VVM) reading of each vaccine. Also, about 13 $(92.9 \%)$ of respondents had Good level of knowledge about vaccine cold chain management as shown in (Table $3)$.
Table 3. Knowledge of respondents about cold chain, Bahir Dar Town, 2019.

\begin{tabular}{lllll}
\hline Ser No & Variable & Response & Frequency & Percent \\
\hline \multirow{3}{*}{301} & Knowing which & Yes & 9 & 64.3 \\
& vaccine are heat & No & 5 & 35.7 \\
& sensitive & & 9 & 64.3 \\
302 & Knowing correct & Yes & 5 & 35.7 \\
& storage temp. $\left(2-8^{\circ} \mathrm{C}\right)$ & No & 5 & 100.0 \\
\multirow{3}{*}{303} & Store keeper knows & Yes & 14 & 0 \\
& freezing is harmful & No & 0 & 92.9 \\
& Correct placing of & Yes & 13 & 7.1 \\
304 & thermometer & No & 1 & 78.6 \\
& Correctly interpreted & Yes & 11 & 21.4 \\
305 & temperature reading & No & 3 & 85.7 \\
& Correctly Conducting & Yes & 12 & 14.3 \\
306 & shake test & No & 2 & 100.0 \\
& Correctly interpreting & Yes & 14 & 0 \\
\hline
\end{tabular}

Vaccine cold chain management practice

Concerning to vaccine cold chain management practice, 9 (64.3\%) of the health facility had a functional thermometer. From the total of health facility all health facility had functional refregrators and most of the facility had the backup generators. All health facility stored the vaccines based on the recommended vaccine storage temperature range $\left(+2^{\circ} \mathrm{C}\right.$ to $\left.+8^{\circ} \mathrm{C}\right), 71.4 \%$ of health facilities were monitor temperature twice daily and all facility arranged the vaccine properly in the refrigerator. More than $21 \%$ the health facility had expired vaccine at a time of data collection in the refrigerators.

More than two third of the 14 health facility apply First Expiry First out (FEFO) principle (the method of vaccine management involves issuing products with the earliest expiry date first, regardless of the order in which they are received) to reduce vaccine wastage. From 14 health facilities, most of them had sufficient storage capacity for the vaccine. $71.4 \%$ of the health facility had separate storage area and the cold room were clean, free of dirt. $57.1 \%$ of the health facility had vaccines in good VVM status, and no health facility that stored anything other than the vaccine in refrigerator.

Factors associated with vaccine cold chain management practice

The finding of this study revealed that 10 (71.4\%) had cold chain management that conforms to the required standards and the rest $4(28.6 \%)$ had improper management practice.

Among the factors, only work experience and level of knowledge on vaccine cold chain management had a statistically significant association with the practice of health workers on cold chain management. Years of experience, overall knowledge of respondents on cold chain management, sufficient storage area and qualification of the health worker was included in the regression model. The adjusted model indicated that respondents who had good level knowledge were 2.6 times more likely to have proper cold chain management practice as compared with those who had not. Health workers whose work experience more than two years were about 5 times more likely to have proper practice on cold chain management compared to their counterpart. 
Table 4. Bivariate and Multivariate Analysis of Providers' Cold Chain Management in the Study Areas, 2019.

\begin{tabular}{|c|c|c|c|c|}
\hline \multirow[t]{2}{*}{ Characteristics } & \multicolumn{2}{|c|}{ Management practice of cold chain } & \multirow{2}{*}{ Crude OR (95\% CI) } & \multirow{2}{*}{ Adjusted OR (95\% CI) } \\
\hline & Proper practice & Improper practice & & \\
\hline \multicolumn{5}{|l|}{ Years of service in years } \\
\hline $1-2$ years & $0(0 \%)$ & $2(14.28)$ & 1.0 & 1.0 \\
\hline$>2$ years & $4(28.57)$ & $8(57.15)$ & $5.2(1.4-19.14)$ & $5.2(1.4-19.14)$ \\
\hline \multicolumn{5}{|l|}{ Knowledge } \\
\hline Good level of knowledge & $0(0 \%)$ & $1(7.14 \%)$ & 1.0 & 1.0 \\
\hline poor level of knowledge & $4(28.58)$ & $9(64.28 \%)$ & $1.97(0.77-5.03)$ & $1.97(0.77-5.03)$ \\
\hline
\end{tabular}

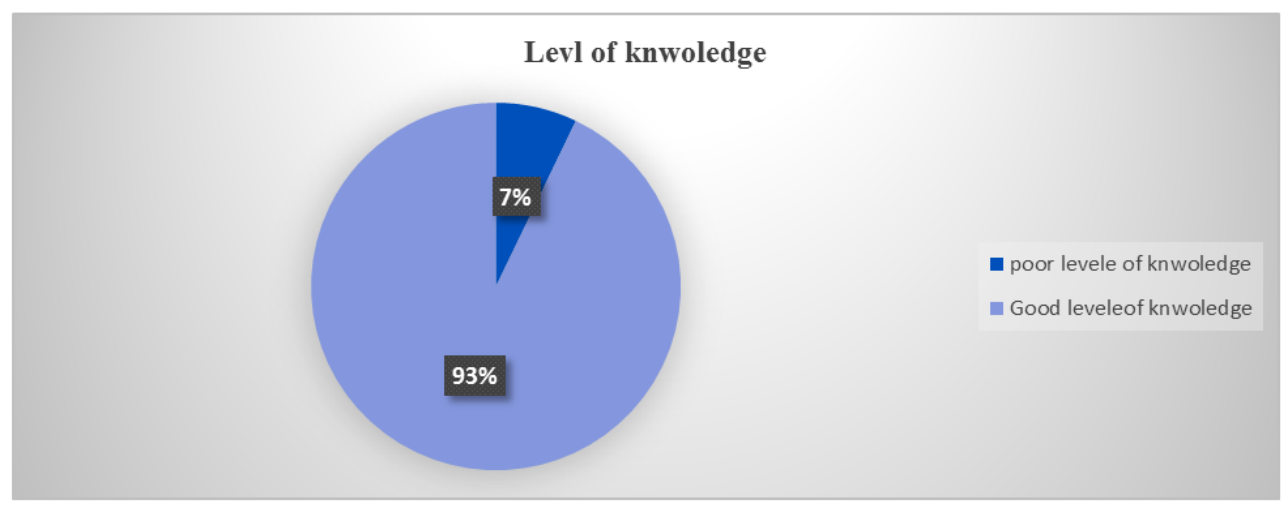

Figure 1. Knowledge of respondents about cold chain status in Bahir Dar city health institution, 2019.

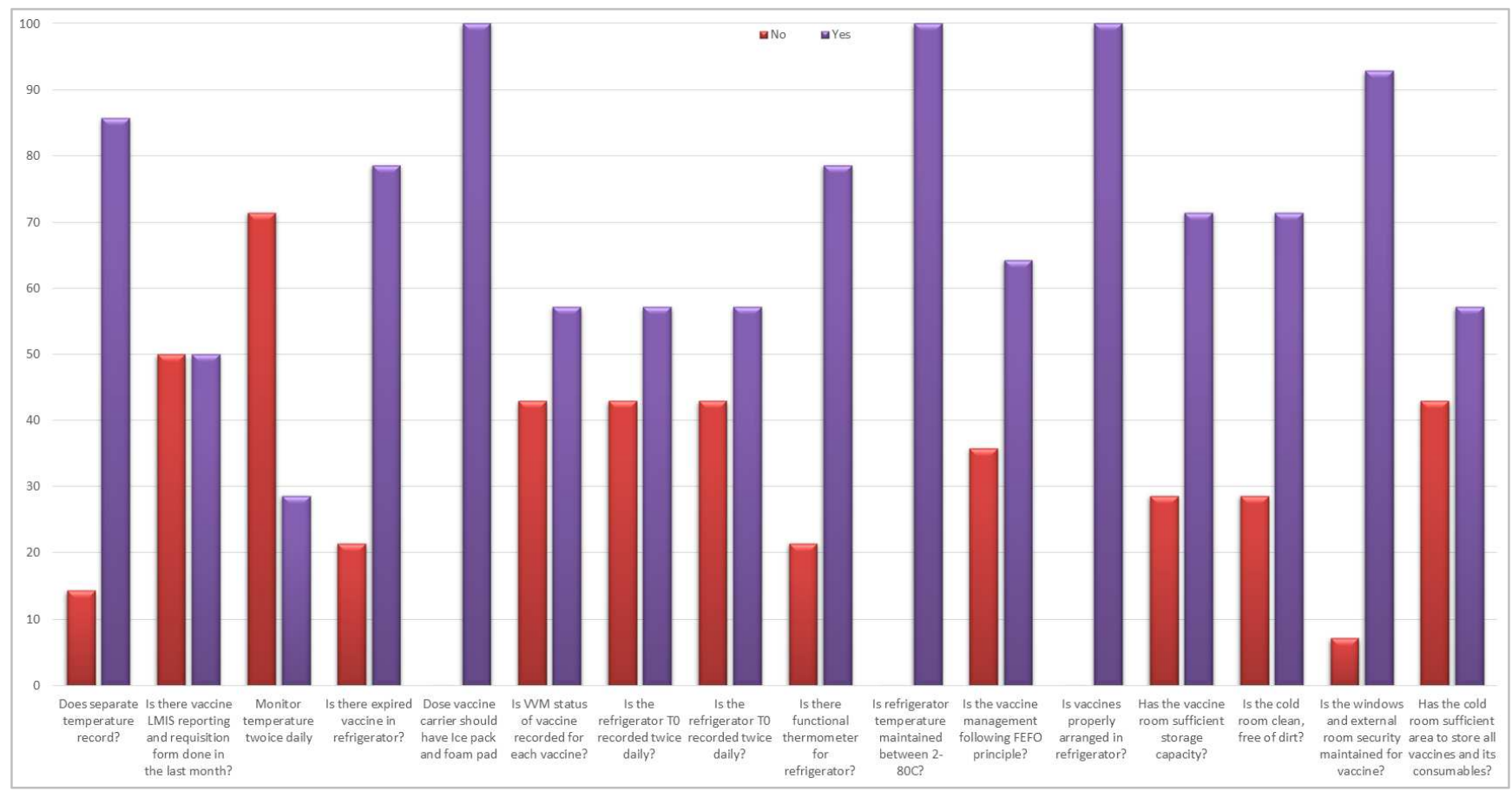

Figure 2. Vaccine cold chain management practice of the health care worker in Bahir Dar city health institution, 2019.

\section{Discussion}

In order to assess the cold chain management practice of the health facilities some variables were used. Based on this the study identified the gaps related to cold chain management practice. There were gaps in following the cold chain management principles such as availability of functional thermometers, availability of guide line, functional backup generator in the facility and use of EEFO principle, recording damaged vaccine, recording temperature twice daily, and recording VVM status for each vaccine

Similarly, the majority of the health facilities did not recorded the refregrators temperature twice daily and they did not have a separate room for vaccine storage. Their storage capacities were insufficient to accommodate all vaccines and its consumable supplies, even though almost all storage area windows and external room had secured. 
Infrastructures were not fulfilled in room to handle the vaccine properly. This inappropriate handling of the vaccine and unavailability of the equipment all has a negative effect on the potency and efficacy of the vaccine $[2,8,20]$. According to the National Standards for Vaccine Storage and Transportation for Immunization Providers of New Zealand, 2017, maintaining correct temperatures during storage and transport of vaccines is a critical task for the health worker. Temperatures must be regularly measured and recorded in order to ensure storage of all vaccines at the correct temperature conditions, and ensure the correct operation of the cold chain equipment. Monitoring of temperatures should be a routine activity, and a task that is carried out at the start and end of each working day [18, 21, 22].

In this study, out of 14 health facilities, only $9(64.3 \%)$ had functional thermometer. In order to effectively maintain the cold chain system, there should be at least one functional thermometer to control the temperature of refrigerator in every day in the health facility since these facilities are expected to provide vaccination services for their communities on a daily basis the must regulate the temperature of the refrigerator in order to maintain the potency of the vaccine [23, 24].

From the total health facility 28.6 reported that they did not have backup generator to use during the interruption of electricity this the big challenge to store the vaccine in the recommended temperature. Since electric supply is not available regularly, availability of backup generator should be a prerequisite for maintenance of vaccine potency and sustainability of immunization service delivery. A study that was conducted to evaluate the cold chain status at immunization centres in Ethiopia in 2019 showed comparable findings 35\% had a functional generator for backup service but the rest facility did not have generator for their refrigerators $[8,13]$.

The finding of this study showed that all health care provider knew the correct and recommended temperature to store the vaccine. The result is higher than as compared with the study done in Cameroon which had $32.7 \%$ study conducted in Ethiopia which was 48.3 [8, 12].

The cold chain monitoring status in this study area was inadequate to ensure proper vaccine storage. In this study, health personnel cold chain management practices was inadequate to support maintenance of effective cold chain standards, which means there were cold chain management practice gaps as per effective vaccine management standards. Only $28.6 \%$ of the health facility which had proper vaccine cold chain management practice. This finding is very low when compare with study done in Saudi, Nigeria and Ethiopia $90 \%, 66.1 \%, 58.3 \%$ and $67.8 \%$ of the facility had appropriate vaccine cold chain management practice $[1,8$, $19,25,26]$. The possible reason for this gap is in adequacy and unavailability of the equipment and infrastructure that is important to the good management practice of cold chain. The finding of this study show that most of the health workers had good level of knowledge on cold chain management practice, which is higher than the finding in the study in East Gojam 38.3\% [8, 19, 27].
The possible potential factors which is responsible for this low level of cold chain management practices include year of experience in the immunization program and level of knowledge showed a statistically significant association with cold chain management practice $(\mathrm{P}<0.05)$. The study in Nigeria and Ethiopia showed that Level of Knowledge was a factor affecting cold chain management practice $[8,25]$. Still the result found from the current study was minimal and needs a big attention by the management units and the stakeholders because during the assessment, in most of the facilities, there were no sufficient storage area, clean and dry room, functional thermometer and there is no generator for backup. Even some of facility had no reporting and requisition form and the other facility did not monitor temperature twice daily. In addition some of them had no availability of guideline especially if the power interruption was for longer period of time.

\section{Conclusion}

The basis for any cold chain management activity is maintaining of the product with in recommended storage condition to administer potent and quality vaccines to clients. In general, the findings of this study indicate that there were important gaps of the health workers in managing the cold. Most cold rooms have insufficient storage capacity and incomplete equipment for adequate cold chain maintenance. Vaccine cold chain management was significantly associated with the overall cold chain management knowledge and work experience of a health care worker in health facility.

To maintain a safe and effective cold chain further efforts are needed both in education and training with improving health worker knowledge and with improving both infrastructure capacity and appropriate equipment. In addition, the regional health bureau and district health office should work on different capacity building activities to health professionals in order to address the knowledge gap at a different level of the health workers.

\section{List of Abbreviation}

\author{
CCP: Cold Chain Points \\ EPI: Expanded program of Immunization \\ ILR: Ice-Lined Refrigerator \\ PFSA: Pharmaceutical Fund Supply Agency \\ VRF: Vaccine Requisition Form \\ VVM: Vial Vaccine Monitoring \\ UNICEF: United Nation Children's Fund \\ WHO: Word Health Organization
}

\section{Consent for Publication}

Not applicable.

\section{Availability of Data and Materials}

All the required data will be available up on the request to the primary investigator. 


\section{Competing Interests}

We authors want to declare that we have no any competing interests.

\section{Funding}

No funding was obtained to carry out the present study.

\section{Authors' Contributions}

SM; Designed the study and carried out statistical analysis. SM; GT; HD: contributed to the designing of the methodology, analysis of the data, add important intellectual content and finally prepared the manuscript. All authors agreed and approved the final manuscript.

\section{Acknowledgements}

We authors would like to forward our heartfelt gratitude to study subjects for their willingness to participate in our study. In addition, we are adding our unlimited thanks to the Bahir Dar University for securing ethical issues of the study

\section{References}

[1] M, M. K. and A. W. S. M, Evaluation of the availability of cold chain tools and an assessment of health workers practice in dammam. J Family Community Med, 2009. 16 (3): p. 83-8.

[2] Kedar G., C. M., Paragkumar D., Dipak M., Study of cold chain management system. International Journal of Medical Science and Public Health | 2016 | Vol 5 | Issue 102130.

[3] WHO - UNICEF, Estimates of immunization coverage: the Federal Democratic Republic of Ethiopia Update of 22 July 2011.

[4] Teklay K., A. Y., Yodit S., Tesfaye B., Hiywet M., Tesfanesh B., Filimona B., Daniel B., Nehimie M., Babaniyi O., National EPI Coverage Survey report in Ethiopia. Ethiopia. J. Health Dev 2006; 22: 2 (PP 146-215).

[5] World Health organization Immunization, Vaccines and Biologicals IVB Catalogue. (2007).

[6] Amily, A. S., F. Lami, and Y. Khader, Impact of Training of Primary Health Care Centers' Vaccinators on Immunization Session Practices in Wasit Governorate, Iraq: Interventional Study. JMIR Public Health Surveill, 2019.5 (4): p. e14451.

[7] Agueh et al. Evaluation of the performance of expanded immunization programme supply chain and logistics management in Southern Benin Rural Health District. Universal Journal of public Health, 2016. 4 (4): p. 162-170.

[8] H. A., A. F. Amhare, and A. A. Bogale, Assessment of factors affecting vaccine cold chain management practice in public health institutions in east Gojam zone of Amhara region. BMC Public Health, 2019. 19 (1): p. 1433.

[9] Kumar, G. and S. Gupta, Assessment of cold chain equipments and their management in government health facilities in a District of Delhi: A cross-sectional descriptive study. Indian J Public Health, 2020. 64 (1): p. 22-26.

[10] OI, J., An assessment of the cold chain system in immunization centres in enugu north local government area of Enugu state. (2013), 3. 4-8.

[11] Wen, Z., et al., Cold Chain Logistics Management of Medicine with an Integrated Multi-Criteria Decision-Making Method. Int J Environ Res Public Health, 2019. 16 (23).

[12] Yakum, M. N., et al., Factors associated with the exposure of vaccines to adverse temperature conditions: the case of North West region, Cameroon. BMC Res Notes, 2015. 8: p. 277.

[13] Yemane B., a. M. D. M., Cold chain status at immunization. East African medical journal. 2000, volume 77/9. 2-6.

[14] FMOH Health Sector Development Program (HSDP) IV, 2010/11 - 2014/15

[15] WHO, Immunization in Practice (IIP), Module for Health Staff, 2004

[16] Joao C. T. M., Gunnar B, Cold chain management: Knowledge and Practice in Primary health care facilities in Niassa, Mozambique. Ethiopia. J. Health Dev. 2007; 21: 2.

[17] Najjar, Z., et al., Surveillance methods to detect the impact of a significant cold chain breach. Vaccine, 2019. 37 (30): p. 3950-3952.

[18] Ng, C. Z., et al., Cold chain time- and temperature-controlled transport of vaccines: a simulated experimental study. Clin Exp Vaccine Res, 2020.9 (1): 8-14.

[19] Yassin, Z. J., et al., Knowledge of Health Professionals on Cold Chain Management and Associated Factors in Ezha District, Gurage Zone, Ethiopia. Scientifica (Cairo), 2019. 2019: p. 6937291.

[20] Kartoglu, U. and J. Milstien, Tools and approaches to ensure quality of vaccines throughout the cold chain. Expert Rev Vaccines, 2014.13 (7): 843-54.

[21] Health, M. o., National Standards for Vaccine Storage and Transportation for Immunisation Providers 2017. 2019.

[22] Hibbs, B. F., et al., Safety of vaccines that have been kept outside of recommended temperatures: Reports to the Vaccine Adverse Event Reporting System (VAERS), 2008-2012. Vaccine, 2018. 36 (4): p. 553-558.

[23] Osei, E., M. Ibrahim, and G. Kofi Amenuvegbe, Effective Vaccine Management: The Case of a Rural District in Ghana. Adv Prev Med, 2019: p. 5287287.

[24] Thielmann, A., et al., Vaccine cold chain in general practices: A prospective study in 75 refrigerators (Keep Cool study). PLoS One, 2019. 14 (11): p. e0224972.

[25] Ogboghodo, E. O., et al., Cold chain management practices of health care workers in primary health care facilities in Southern Nigeria. Pan Afr Med J, 2017. 27: p. 34.

[26] Bedasa Woldemichael, Dadei Bekele and Adem Esmael Cold Chain Status and Knowledge of Vaccine Providers at Primary Health Care of Units Bale Zone, Southeast Ethiopia: Crosssectional Study Immunome Research, 2018. 4 (14).

[27] Lalitha K, A. B., Narayana H. et al., Evaluation of cold chain practice. National Journal of Community Medicine. 2014, 5 (3). 